\title{
Validity of UPREP liquid based cytology in FNAC examination for palpable lesions type of article - original article
}

\author{
Bindhuja J. ${ }^{1}$, Aswathy Jeyachadran ${ }^{2}$ \\ ${ }^{1}$ Dr. Bindhuja J, Assistant Professor, ${ }^{2}$ Dr. Jeyachadran Aswathy, Post Graduate, both authors are affiliated with \\ Department of Pathology, Sri Mookambika Institute of Medical Science, Kanyakumari, Tamilnadu, India.
}

Corresponding Author: Dr. Jeyachandran Aswathy, Post Graduate, Department of Pathology, Sri Mookambika Institute of Medical Science,Kanyakumari, Tamilnadu, India. E-mail: aswathyj8555@gmail.com, johnjennerresearch@gmail.com

\begin{abstract}
Background: Liquid-based cytology (LBC) is a technique that enables cells to be suspended in a monolayer, through which better morphological assessment is possible. There are very few studies done to evaluate the outcomes between conventional and UPREP LBC method. A successful validation of UPREP LBC will go a long way in providing both affordable and accurate management of cancers in developing countries. Methods: This study was carried out as a comparative study among 110 all adults who were advised to undergo Fine Needle Aspiration Cytology (FNAC) examination for palpable lesions in thyroid, breast and lymph node in our tertiary care hospital. Conventional FNAC was taken for 55 participants and for the UPREP LBC group (55 participants), the same procedure was repeated and instead of air, preservative solution was drawn into the syringe. Various cytological parameters including cellularity, background, monolayer, cellular morphologic change, nuclear changes and inflammatory infiltrate were studied. Results: Among the individual lesions involving breast, thyroid and lymph node, breast carcinoma was highest in both the groups (25.4\%) followed by fibroadenoma of the breast (20\%) and Hashimoto's thyroiditis (18.2\%). Statistically significant differences were observed between the conventional and UPREP groups. Informative background was increasingly better in the conventional group compared to the UPREP group $(\mathrm{p}<0.001)$ while background debris was absent in most of the patients in UPREP group $(\mathrm{p}<0.001)$. Details pertaining to nucleus and cytoplasm were better perceived in the UPREP group compared to the conventional group $(\mathrm{p}<0.001)$. Conclusion: Manual liquid based cytology like UPREP LBC is an accurate, less expensive alternative procedure to automated LBC with the advantage of providing monolayer, absence of obscuring blood or debris, better nuclear and cytoplasmic morphology.
\end{abstract}

Key words: Breast cancer, Cytology, Fine Needle Aspiration, Thyroiditis, UPREP

\section{Introduction}

Cancer is the leading cause of death worldwide, accounting for 8.8 million deaths in 2015 alone. Globally, nearly 1 in 6 deaths is due to cancer. Approximately $70 \%$ of cancer deaths occur in low- and middle-income countries [1]. The number of new cancer cases is expected to rise by about $70 \%$ over the next 2 decades with more than $60 \%$ of world's total new annual cases occurring in Africa, Asia and Central and South America. These regions also account for $70 \%$ of the world's cancer deaths.

The most common cancers resulting in death worldwide are cancers of Lung (1.69 million deaths), Liver (788 000 deaths), Colorectal (774 000 deaths), Stomach (754 000 deaths), Breast (571 000 deaths)[1].

\footnotetext{
Manuscript received: $30^{\text {th }}$ April 2019

Reviewed: $10^{\text {th }}$ May 2019

Author Corrected: $17^{\text {th }}$ May 2019

Accepted for Publication: $21^{\text {st }}$ May 2019
}

Cancers arise from the transformation of normal cells into tumour cells in a multistage process that encompasses the stepwise accumulation of multiple mutations that act in a complementary way. These changes are the result of the interaction between a person's genetic factors and one or more of the three types of external agents namely physical carcinogens like ionizing radiation and ultraviolet rays, chemical carcinogens like tobacco smoke, aflatoxins, asbestos, arsenic, or biological agents including certain viruses and bacteria.

The incidence of cancer rises dramatically with age, due to a build-up of risks for specific cancers that increase with age. The overall risk accumulation is combined with less effective cellular repair mechanisms as a person grows older. Although the burden and impact of cancers are high, studies have proven that $30-50 \%$ of 
the cancers can be prevented by avoiding or minimizing the risk factors like lifestyle changes and early detection and timely management. Early detection is feasible by creating adequate awareness to the masses, appropriate clinical diagnosis and staging, and accessible treatment [1].

One of the forerunners in early diagnosis is Fine Needle Aspiration Cytology (FNAC). Fine Needle Aspiration Cytology (FNAC) when used alongside clinical and radiological assessment offers a relatively cheap, quick, and accurate tool for the diagnosis of cancer [2]. Due to its low cost, it is also being used for the differential diagnosis between benign and malignant lesions in the primary care units of many underdeveloped countries [3]. For many years, efforts have been made to develop methods to enhance the sensitivity and specificity of cytological smears. This led to the evolution of liquid based preparation of cytological samples.

Liquid-based cytology (LBC) is a technique that enables cells to be suspended in a monolayer, through which better morphological assessment is possible. It includes the preparation and evaluation of cells collected in a liquid fixative. The cells are then transferred in a representative manner in order to avoid operator dependent variation.

Though initially advised for gynaecology samples, it is increasingly being used for non-gynaecologic cytology samples and FNA samples also [4,5]. Two Food and Drug Administration (FDA) approved technologies Thin Prep (Cytyc Corp.) and Sure Pap (Tripath imaging, Inc.) are being widely used for $\mathrm{LBC}[6]$.

\section{Original Research Article}

Compared with conventional preparation, Liquid based Preparation has a number of advantages with regard to nuclear and cytoplasmic morphology, cell size and background material. Liquid based Preparation also allows for rapid fixation, decreased obscuring factors and standardization of cell transfer.

The advantages of liquid-based cytology also include improved sensitivity and specificity, since fixation is better and nuclear details are well preserved. Abnormal cells are not obscured or diluted by other epithelial or inflammatory cells. There is, therefore, a lower rate of unsatisfactory cytology samples $[5,7]$. The residual cell suspension can also be used to make further cytological preparations. More over immunocytochemistry can also be performed on the residual sample [8].

Owing to the high cost of setup, manual methods of liquid based cytology are under evaluation. UPREP liquid based cytology system is a new and advanced system in the Manual Liquid based Preparation. The principle behind UPREP Liquid based Cytology procedure is surface adsorption by Relative Centrifugal Force (RCF)[6]. There are very few studies done to evaluate the outcomes between conventional and UPREP LBC method. A successful validation of UPREP LBC will go a long way in providing both affordable and accurate management of cancers in developing countries.

\section{Objectives}

This study was carried out to compare FNAC smears made by conventional preparation and UPREP liquid based preparation.

\section{Methodology}

Study setting: This study was carried out as a comparative study in the Department of Pathology of our tertiary care hospital for a period of one and a half years between January 2016 and June 2017.

Study population: The study population comprised of all men and women in the age group of 20-60 years attending the outpatient clinic of Department of General Surgery of our tertiary care hospital who were advised to undergo FNAC examination.

Inclusion Criteria: Patients attending General Surgery Out Patient Department (OPD) of in our hospital with palpable lesions in thyroid, breast and lymph node who were sent for fine needle aspiration study.

\section{Exclusion Criteria}

1. Patients who were not willing to participate.

2. Patients who have undergone chemotherapy / radiotherapy.

Sample size and sampling: Based on the available literature, the probability of good outcome using cell Prep Plus was $73 \%$ while the same using Thin Prep was 50\%. ${ }^{[9]}$ At $95 \%$ confidence limits and $80 \%$ power, the sample size for each group was calculated as 55 and total of 110 samples were recruited for the study. All the participants who fulfilled the selection criteria were randomly assigned into conventional smear group and UPREP liquid based preparation group, each consisting of 55 participants. 


\section{Original Research Article}

Ethical approval and informed consent: Approval was obtained from Institutional Ethics committee prior to the commencement of the study. Each participant was explained in detail about the study and informed consent was obtained prior to the data collection.

Data collection: After a detailed history, and thorough clinical examination, the skin over the area to be sampled was disinfected using alcohol swab. FNA was done using standard disposable syringes fitted with $23 \mathrm{G}$ needle. The lesion was palpated and fixed between the left index and middle finger (in case of small lesions) of the examiner. Needle positioned within the target tissue.Plunger was pulled to apply negative pressure, needle moved back and forth inside target lesion.

Negative pressure was released while needle remained in target tissue and then the needle was withdrawn. Needle was then detached and air was drawn into syringe. One small drop of sample was blown onto a microscopy slide and then the smear was made. Then it was immediately placed in alcohol for fixation. This was the first pass and this slide was stained with pap stain (conventional preparation).

For the UPREP LBC group, the same procedure was repeated and instead of air, preservative solution was drawn into the syringe. The needle with aspirated material was attached to syringe, plunger pushed down gently to expel the material along with preservative into a conical plastic screw capped container. The syringe was washed two to three times with the preservative to make sure no material remained in the syringe. The sample was then kept as such for 30 minutes. The preserved sample was then centrifuged in a Swinging type centrifuge at 1000 RPM for 10 minutes. The supernatant was discarded and then the pellet was agitated to get the homogenous sample. One or two drops of preservative solution were further added over the pellet and mixed well. A drop of fixative solution was added to the slide and $50 \mu 1$ of the diluted sample was smeared over them. The smear was allowed to air dry and staining was done.

The parameters studied in the smear by microscopy were cellularity, background, monolayer, cellular morphologic change (architectural and cytoplasmic distortion, cytoplasmic vacuolation, cellular elongation, folded cytoplasmic borders), nuclear changes (nuclear hyperchromasia, coarse chromatin, prominent nucleoli, irregular nuclear borders, atypical mitosis) and Inflammatory infiltrate.

The cells were sampled by tissue sampling and were studied under light microscope. UPREP LBC kit marketed by Regenix Drugs LTD, \#11, First Floor, Loganathan Nagar, $3^{\text {rd }}$ Street, Choolaimedu, Near MMMDA Metro Station, Chennai- 600094. E mail: www.info@uprepindia.com

Chemicals used for staining procedures included Xylene, alcohol, DPX, frosted microslide $75 \mathrm{~mm}$ long, $25 \mathrm{~mm}$ wide, and $1.25 \mathrm{~mm}$ thick and Microscopic cover glass $22 \mathrm{~mm} \times 22 \mathrm{~mm}$.

Enumeration: The stained smears were seen under A Delta Plan $\mathrm{Z}^{\mathrm{TM}} \mathrm{AP} 40$ with APCAM-5 Binocular Charged Couple Device (CCD) attached microscope. They were then scored according to the semi quantitative scoring system.

Table-1: Semi quantitative Scoring system used in FNA Smears

\begin{tabular}{|c|c|c|c|c|}
\hline Cytological features & Score 0 & Score 1 & Score 2 & Score 3 \\
\hline Cellularity & Zero & Scanty & Adequate & Abundant \\
\hline Background blood \&debris & Zero & occasional & Good amount & \\
\hline $\begin{array}{c}\text { Informative background (Colloid, } \\
\text { Mucus, and Stromal fragments). }\end{array}$ & Absent & Present & ----- & ----- \\
\hline Monolayer & Absent & Occasional & Good amount & ------ \\
\hline Cell architecture & $\begin{array}{c}\text { Non } \\
\text { Recognised }\end{array}$ & $\begin{array}{c}\text { Moderately } \\
\text { Recognised }\end{array}$ & $\begin{array}{c}\text { Well } \\
\text { Recognised }\end{array}$ & ----- \\
\hline Cytoplasmic details & Poor & Fair & Good & Excellent \\
\hline Nuclear details & Poor & Fair & Good & Excellent \\
\hline
\end{tabular}

Statistical Analysis: Data was entered and analyzed using SPSS software. The outcome of staining was expressed in percentages. Comparison between the two groups was carried out by Independent Sample $t$ test. 


\section{Results}

\section{Original Research Article}

This study was carried out among 110 participants, with 55 in each group. Majority of the participants in both the groups belonged to 40-49 years of age (45.5\%). Majority of the participants were females in both the groups (96.4\%). Lesions of the thyroid was predominant in both the groups (29.1\%) followed by breast lesions (45.5\%). (Table 1$)$

Among the individual lesions involving breast, thyroid and lymph node, breast carcinoma was highest in both the groups (25.4\%) followed by fibroadenoma of the breast (20\%) and Hashimoto's thyroiditis (18.2\%). (Table 2)

Table-1: Background Characteristics.

\begin{tabular}{|c|c|c|c|c|c|}
\hline \multirow[t]{2}{*}{ S.No } & \multirow{2}{*}{$\begin{array}{l}\text { Background } \\
\text { characteristics }\end{array}$} & \multicolumn{2}{|c|}{ Conventional group } & \multicolumn{2}{|c|}{ UPREP group } \\
\hline & & Frequency N(55) & $\begin{array}{c}\text { Percentage } \\
(\%)\end{array}$ & $\begin{array}{c}\text { Frequency } \\
\mathbf{N}(55)\end{array}$ & $\begin{array}{c}\text { Percentage } \\
(\%)\end{array}$ \\
\hline 1 & \multicolumn{5}{|c|}{ Age } \\
\hline & $10-19$ & 2 & 3.6 & 2 & 3.6 \\
\hline & $20-29$ & 8 & 14.5 & 8 & 14.5 \\
\hline & $30-39$ & 11 & 20.1 & 11 & 20.1 \\
\hline & $40-49$ & 19 & 34.5 & 19 & 34.5 \\
\hline & $50-59$ & 9 & 16.4 & 9 & 16.4 \\
\hline & $60-69$ & 6 & 10.9 & 6 & 10.9 \\
\hline \multirow[t]{3}{*}{2} & \multicolumn{5}{|c|}{ Sex } \\
\hline & Female & 53 & 96.4 & 53 & 96.4 \\
\hline & Male & 2 & 3.6 & 2 & 3.6 \\
\hline \multirow[t]{4}{*}{3} & \multicolumn{5}{|c|}{ Site } \\
\hline & Breast & 25 & 45.5 & 25 & 45.5 \\
\hline & Thyroid & 27 & 49.1 & 27 & 49.1 \\
\hline & Lymph node & 3 & 5.5 & 3 & 5.5 \\
\hline
\end{tabular}

This study was carried out among 110 participants, with 55 in each group. Majority of the participants in both the groups belonged to 40-49 years of age (45.5\%). Majority of the participants were females in both the groups (96.4\%). Lesions of the thyroid was predominant in both the groups (29.1\%) followed by breast lesions (45.5\%). (Table 1)

Table-2: Diagnosis in both conventional and UPREP groups.

\begin{tabular}{|c|c|c|c|c|c|}
\hline \multirow[t]{2}{*}{ SNo } & \multirow[t]{2}{*}{ Diagnosis } & \multicolumn{2}{|c|}{ Conventional group } & \multicolumn{2}{|c|}{ UPREP group } \\
\hline & & $\begin{array}{l}\text { Frequency } \\
\quad \mathbf{N}(\mathbf{5 5})\end{array}$ & $\begin{array}{c}\text { Percentage } \\
\qquad(\%)\end{array}$ & $\begin{array}{l}\text { Frequency } \\
\quad \mathbf{N}(\mathbf{5 5})\end{array}$ & $\begin{array}{c}\text { Percentage } \\
(\%)\end{array}$ \\
\hline 1 & Breast fibroadenoma & 11 & 20.0 & 11 & 20.0 \\
\hline 2 & Breast carcinoma & 14 & 25.4 & 14 & 25.4 \\
\hline 3 & Thyroid benign & 8 & 14.5 & 8 & 14.5 \\
\hline 4 & Hashismotos thyroiditis & 10 & 18.2 & 10 & 18.2 \\
\hline 5 & $\begin{array}{c}\text { Follicular Lesion of Undetermined } \\
\text { Significance (FLUS) }\end{array}$ & 6 & 10.9 & 6 & 10.9 \\
\hline 6 & Papillary thyroid carcinoma & 3 & 5.5 & 3 & 5.5 \\
\hline 7 & Reactive Lymph node & 3 & 5.5 & 3 & 5.5 \\
\hline
\end{tabular}

Among the individual lesions involving breast, thyroid and lymph node, breast carcinoma was highest in both the groups (25.4\%) followed by fibroadenoma of the breast (20\%) and Hashimoto's thyroiditis (18.2\%). (Table 2) 


\section{Original Research Article}

Table-3: Cytological features between the two groups.

\begin{tabular}{|c|c|c|c|c|c|}
\hline \multirow[t]{2}{*}{ S No } & \multirow[t]{2}{*}{ Background characteristics } & \multicolumn{2}{|c|}{ Conventional group } & \multicolumn{2}{|c|}{ UPREP group } \\
\hline & & $\begin{array}{c}\text { Frequency } \\
\text { N (55) }\end{array}$ & $\begin{array}{c}\text { Percentage } \\
(\%)\end{array}$ & $\begin{array}{c}\text { Frequency } \\
\text { N (55) }\end{array}$ & $\begin{array}{c}\text { Percentage } \\
(\%)\end{array}$ \\
\hline 1 & \multicolumn{5}{|c|}{ Cellularity } \\
\hline & Adequate & 17 & 30.9 & 20 & 36.4 \\
\hline & Abundant & 38 & 69.1 & 35 & 63.6 \\
\hline \multirow[t]{3}{*}{2} & \multicolumn{5}{|c|}{ Informative background } \\
\hline & Absent & 2 & 3.6 & 40 & 72.7 \\
\hline & Present & 53 & 96.4 & 15 & 27.3 \\
\hline \multirow[t]{4}{*}{3} & \multicolumn{5}{|c|}{ Background debris } \\
\hline & Absent & 30 & 54.5 & 53 & 96.4 \\
\hline & Scanty & 22 & 40.0 & 2 & 3.6 \\
\hline & Abundant & 3 & 5.5 & 0 & 0 \\
\hline \multirow[t]{3}{*}{4} & \multicolumn{5}{|c|}{ Inflammatory cells } \\
\hline & Absent & 23 & 41.8 & 42 & 76.4 \\
\hline & Present & 32 & 58.2 & 13 & 23.6 \\
\hline \multirow[t]{4}{*}{5} & \multicolumn{5}{|c|}{ Monolayer } \\
\hline & Absent & 9 & 16.4 & 0 & 0 \\
\hline & Occasional & 44 & 80 & 1 & 1.8 \\
\hline & Abundant & 2 & 3.6 & 54 & 98.2 \\
\hline \multirow[t]{4}{*}{6} & \multicolumn{5}{|c|}{ Cell architecture } \\
\hline & Absent & 13 & 23.6 & 3 & 5.5 \\
\hline & Occasional & 38 & 69.1 & 40 & 72.7 \\
\hline & Abundant & 4 & 7.3 & 12 & 21.8 \\
\hline \multirow[t]{4}{*}{7} & \multicolumn{5}{|c|}{ Cytoplasm } \\
\hline & Not clear & 12 & 21.8 & 3 & 5.5 \\
\hline & Clear & 30 & 54.5 & 0 & 0 \\
\hline & Very clear & 13 & 23.7 & 52 & 94.5 \\
\hline \multirow[t]{4}{*}{8} & \multicolumn{5}{|c|}{ Nucleus details } \\
\hline & Not clear & 13 & 23.6 & 3 & 5.5 \\
\hline & Clear & 28 & 50.9 & 4 & 7.3 \\
\hline & Excellent details & 14 & 25.5 & 48 & 87.2 \\
\hline
\end{tabular}

The comparison of cytological features between the two groups is given in table 3 . Abundant cellularity was found to be high among the conventional group (691\%) compared to the UPREP group (63.6\%).

Similarly informative background was greater for the conventional group (96.4\%) compared to UPREP group (27.3\%). Background debris was increasingly absent in UPREP group (96.4\%) compared to the conventional group (54.5\%).

Similarly cytoplasm was very clear in majority of the slides in UPREP group $(94.5 \%)$ compared to the conventional group $(23.7 \%)$.

Moreover UPREP group showed excellent nuclear details is most of the participants (87.2\%) compared to the conventional group $(25.5 \%)$. 


\section{Original Research Article}

Table-4: Association between cellular characteristics and the study groups.

\begin{tabular}{|c|c|c|c|c|c|c|c|c|}
\hline \multirow{2}{*}{$\begin{array}{l}\text { S. } \\
\text { No }\end{array}$} & \multirow[t]{2}{*}{ Characteristic } & \multirow{2}{*}{$\begin{array}{c}\text { Total } \\
110\end{array}$} & \multicolumn{4}{|c|}{ Group } & \multirow[t]{2}{*}{ Chi Sq } & \multirow[t]{2}{*}{ P value } \\
\hline & & & $\begin{array}{c}\text { Conventional } \\
\mathbf{N}(55)\end{array}$ & $(\%)$ & $\begin{array}{c}\text { UPREP } \\
\text { N(55) }\end{array}$ & $(\%)$ & & \\
\hline 1 & \multicolumn{8}{|c|}{ Informative background } \\
\hline & Absent & 42 & 2 & $(4.8)$ & 40 & $(95.2)$ & \multirow[t]{2}{*}{55.61} & \multirow[t]{2}{*}{$0.001 *$} \\
\hline & Present & 68 & 53 & $(77.9)$ & 15 & $(22.1)$ & & \\
\hline 2 & \multicolumn{8}{|c|}{ Comparison of background debris } \\
\hline & Absent & 83 & 30 & $(36.1)$ & 53 & $(63.9)$ & \multirow{3}{*}{27.389} & \multirow{3}{*}{$0.001 *$} \\
\hline & Scanty & 24 & 22 & $(91.7)$ & 2 & $(8.3)$ & & \\
\hline & Abundant & 3 & 3 & $(100)$ & 0 & 0 & & \\
\hline 3 & \multicolumn{8}{|c|}{ Comparison of inflammatory cells } \\
\hline & Absent & 65 & 23 & $(35.4)$ & 42 & $(64.6)$ & \multirow[t]{2}{*}{13.576} & \multirow[t]{2}{*}{$0.001 *$} \\
\hline & Present & 45 & 32 & $(71.1)$ & 13 & $(28.9)$ & & \\
\hline 4 & \multicolumn{8}{|c|}{ Comparison of monolayer } \\
\hline & Absent & 9 & 9 & $(100)$ & 0 & $(0.0)$ & \multirow{3}{*}{98.375} & \multirow{3}{*}{$0.001 *$} \\
\hline & Occasional & 45 & 44 & $(97.8)$ & 1 & $(2.2)$ & & \\
\hline & Abundant & 56 & 2 & $(3.6)$ & 54 & $(96.4)$ & & \\
\hline \multirow[t]{4}{*}{5} & \multicolumn{8}{|c|}{ Comparison of cell architecture } \\
\hline & Absent & 16 & 13 & $(81.2)$ & 3 & $(18.8)$ & \multirow{3}{*}{10.301} & \multirow{3}{*}{$0.006^{*}$} \\
\hline & Occasional & 78 & 38 & $(48.7)$ & 40 & $(51.3)$ & & \\
\hline & Abundant & 16 & 4 & $(25.0)$ & 12 & $(75.0)$ & & \\
\hline \multirow[t]{4}{*}{6} & \multicolumn{8}{|c|}{ Comparison of cytoplasmic details } \\
\hline & Not clear & 15 & 12 & $(80.0)$ & 3 & $(20.0)$ & \multirow{3}{*}{58.8} & \multirow{3}{*}{$0.001 *$} \\
\hline & Clear & 30 & 30 & $(100.0)$ & 0 & $(0.0)$ & & \\
\hline & Very clear & 65 & 13 & $(20.0)$ & 52 & $(80.0)$ & & \\
\hline 7 & \multicolumn{8}{|c|}{ Comparison of nucleus details } \\
\hline & Not clear & 16 & 13 & $(81.2)$ & 3 & $(18.8)$ & \multirow{3}{*}{42.895} & \multirow{3}{*}{$0.001 *$} \\
\hline & Clear & 32 & 28 & $(87.5)$ & 4 & $(12.5)$ & & \\
\hline & Excellent details & 62 & 14 & $(22.6)$ & 48 & $(77.4)$ & & \\
\hline
\end{tabular}

Statistically significant differences were observed between the conventional and UPREP groups with respect to almost all the cytological features. Informative background was increasingly better in the conventional group compared to the UPREP group $(\mathrm{p}<0.001)$ while background debris was absent in most of the patients in UPREP group ( $<<0.001)$. Inflammatory cells were predominantly present in specimens examined in conventional group and monolayer was abundant in UPREP group ( $\mathrm{p}<0.001$ ). Details pertaining to nucleus and cytoplasm were better perceived in the UPREP group compared to the conventional group $(\mathrm{p}<0.001)$. (Table 4$)$

The comparison of cytological features between the two groups is given in table 3. Abundant cellularity was found to be high among the conventional group (691\%) compared to the UPREP group (63.6\%). Similarly, informative background was greater for the conventional group (96.4\%) compared to UPREP group (27.3\%). Background debris was increasingly absent in UPREP group (96.4\%) compared to the conventional group (54.5\%). Similarly, cytoplasm was very clear in majority of the slides in UPREP group (94.5\%) compared to the conventional group (23.7\%). Moreover UPREP group showed excellent nuclear details is most of the participants $(87.2 \%)$ compared to the conventional group (25.5\%).

Statistically significant differences were observed between the conventional and UPREP groups with respect to almost all the cytological features. Informative background was increasingly better in the conventional group compared to the UPREP group $(\mathrm{p}<0.001)$ while background debris was absent in most of the patients in UPREP group ( $<<0.001$ ). Inflammatory cells were predominantly present in specimens examined in conventional group and monolayer was abundant in UPREP group ( $\mathrm{p}<0.001)$. Details pertaining to nucleus and cytoplasm were better perceived in the UPREP group compared to the conventional group $(\mathrm{p}<0.001)$. (Table 4$)$ 


\section{Original Research Article}

\section{Discussion}

Currently, FNA has a significant role in the evaluation of palpable lesions, however the success of FNA depends immensely upon correct preparation of cytological smears and skills of the person performing the procedure [10-12]. Gerhard $\mathrm{R}$ et al observed that the number of passes performed and the skill of the person performing the procedure determine to a large extent the quality and cellularity of the FNA samples [13].

Liquid based cytology was approved by FDA in 1996 viz. Thin Prep ${ }^{\mathrm{TM}}$ (TP; Hologic, Marlborough, Mass., USA) and the Sure Path ${ }^{\mathrm{TM}}$ (SP; BD Tri Path, Burlington, N.C., USA) for gynaecological samples. They helped to overcome problems related to poorly prepared and ill preserved smears. Subsequently the use of LBC extended to non-gynaecological samples including FNA and effusion fluids[14].

Many authors have evaluated the both gynaecological and non-gynecological specimens using LBC preparations and have attributed benefits over Conventional Smear (CS) viz., increased cellularity, lack of obscuring background material, improved morphology, and a decrease in the rate of unsatisfactory or less than optimal specimens. From clinician's standpoint, LBC technique is far easier, quicker, and safer and requires less skill. From the pathologist's standpoint, the advantages of using the LBC technique are no to minimal confounding factors (blood, debris and necrotic materials), excellent cell preservation, lesser fixation artifacts (air-drying artifacts), even distribution and less overlapping of the cells and fewer numbers of slides requiring examination.

However, because of the chemical influences of the fixation medium and the physical forces of processing techniques, LBC tends to produce certain cytomorphological alterations and artefacts: smaller cell clusters and sheets and breakage of papillae; more dyscohesive cells; attenuated chromatin details with prominent nucleoli and smaller cell size; intranuclear inclusion is difficult to visualize; altered background matrix in both quantity and quality; aggregation of lymphocytes and markedly decreased number of extracellular particles; and small mononuclear cells, red blood cells, and myoepithelial cells[15].

Hence, there is a need to exercise caution in order to avoidmisinterpretations while reporting FNA prepared using LBC [16]. Garbaret al in his comparative study at two university hospitals concluded that despite the cost, the efficiency of lymph node FNAC is identical between CS and LBC[17].
In this study, conventional smear was prepared from first pass material and Manual Liquid Based Cytology (MLBC) smear was prepared from the second pass material. This was to ensure the cellularity would not be compromised upon. The diagnosis in both groups was the same hence the diagnostic accuracy of UPREP LBC is similar to conventional smear.

Cellularity: In the present study the cellularity for UPREP LBC was almost equivalent to conventional smear. Dey P. et al in their study utilized a separate pass entirely for MLBC, and the cellularity became almost equivalent to CS [18]. Perez-Reyes et al employed split sampling technique where they divided the aspirate into two halves, one for LBC and the other for CS, hence in their study the cellularity of LBC was inferior to CS[19]. Gerhard R et al observed that the number ofpasses performed and the skills of the person performing the procedure determine the quality and cellularity of the samples [13].

Informative Background: The diagnosis of fibroadenoma is rendered on the basis of visualization of ductal cell aggregates, bipolar cells and stromal fragments. In the present study, 11 cases of fibroadenoma were analyzed. CS met the diagnostic criteria in all cases, however UPREP LBC slides showed an absence of fibromyxoid stroma in all except 1 case. Pervez et al concluded that the diagnosis of fibroadenoma seems to be most problematic on LBC preparations [19]. Some studies showed a low diagnostic rate compared to CS and false-positive diagnoses while over-classifying fibroadenomas as atypical or suspicious [10-19,20].

Based on the presence of monolayer, rich cellularity, detailed nuclear features, and clean background, the diagnosis of breast carcinoma was made in the present study. Both LBC and CS preparations had comparable performance for the detection of breast carcinoma. Dey et al. concluded that the diagnosis of ductal carcinoma was easier on LBC due to clean background and detailed nuclear features of tumor cells [18].

Amount of colloid in the background plays an important role in the diagnosis of benign and follicular lesions of thyroid. In this study, the amount of colloid on UPREP LBC was diminished and appeared fragmented, and in droplets. Nuclear grooves and pseudo inclusions were apparent in papillary carcinoma. However, Lee et al.observed that background material were slightly superior in LBC preparation than CS preparation. In thyroid lesions, the present study found that MLBC 
preparations should be interpreted with great caution and CS should always be employed to confirm the diagnosis [21]. Similarly, few workers demonstrated these problems in their study $[7,22,23]$.

Background Debris: The amount of obscuring background debris was almost negligible in UPREP LBC preparations when compared to CS preparation. This resulted in better visualization of cells with greater ease of diagnosis and a reduction in the need for repeat FNAC's [16,17,22,24-26]. In the current study, there was statistically significant differences between CS preparations and UPREP LBCin view of informative background, background debris, inflammatory cells, monolayer, cell architecture, cytoplasm and nucleus details $(p<0.05)$. However, no statistically significant difference was found between these two groups with regard to cellularity $(P>0.05)$.

In the current study, there was statistically significant differences between MLBC and CS preparations in view of absence of blood and debris, presence of monolayers, and preservation of cytoplasmic and nuclear details $(P=0.001)$.

However, no statistically significant difference was found between these two groups with regard to cellularity, informative background, and architecture $(P$ $>0.05)$. These findings were in accordance with the studies done by Tripathyet al., Mygdakoset al., and Dey et al[3-5] Koybasiogluet al[8].

\section{Conclusion}

Fine needle aspiration is a safe and cost effective method for the diagnosis of palpable lesions at various anatomical sites. However, adequate preparation of smears determines the quality of FNA. Manual liquid based cytology like UPREP LBC is an accurate, less expensive alternative procedure to automated LBC with the advantage of providing monolayer, absence of obscuring blood or debris, better nuclear and cytoplasmic morphology. It is prudent to recognize certain distinct changes in LBC smears in order to avoid interpretative errors. Because of that, training before screening and interpreting LBC preparations is highly recommended.

What this study adds to existing knowledge: Although the existing protocol of Fine Needle Aspiration is well established as safe and cost effective method, the scope of manual Liquid based cytology cannot be undermined. Our study has established that manual LBC may be used as an adjunct with conventional preparation, for better interpretation of the slides.

\section{Original Research Article}

\section{Declaration}

Findings: Nil; Conflict of Interest: None initiated Permission from IRB: Yes

\section{Author contribution}

All the authors contributed equally in designing the intellectual content, data acquisition and analysis and literature review.

\section{References}

1. International Agency for Research on Cancer. World Health Organization. Latest global cancer data. [Internet] Available from https://www.who.int/cancer /PR Globocan Final.pdf

2. Roskell DE, Buley ID. Fine needle aspiration cytology in cancer diagnosis. BMJ. 2004 Jul 31;329 (7460): 244-5. DOI:10.1136/bmj.329.7460.244

3. Hutchinson ML, Isenstein LM, Goodman A, et al. Homogeneous sampling accounts for the increased diagnostic accuracy using the ThinPrep Processor. Am J Clin Pathol. 1994 Feb;101(2):215-9. DOI: 10.1093 /ajcp/ 101.2.215

4. Kavatkar AN, Nagwanshi CA, Dabak SM. Study of a manual method of liquid-based cervical cytology. Indian J Pathol Microbiol. 2008 Apr-Jun; 51 (2): 190-4.

5. Karnon J, Peters J, Platt J, et al. Liquid-based cytology in cervical screening: an updated rapid and systematic review and economic analysis. Health Technol Assess. 2004 May;8(20):iii, 1-78.

6. Haghighi F, Ghanbarzadeh N, Ataee M, et al. A comparison of liquid-based cytology with conventional Papanicolaou smears in cervical dysplasia diagnosis. Adv Biomed Res. 2016 Oct 26;5:162. eCollection 2016. DOI:10.4103/2277-9175.192735

7. Tripathy K, Misra A, Ghosh JK. Efficacy of liquidbased cytology versus conventional smears in FNA samples. J Cytol. 2015 Jan-Mar;32(1):17-20. doi: 10. 4103 / 0970-9371.155225.

8. Garbar C, Curé H. Fine-needle aspiration cytology can play a role in neoadjuvant chemotherapy in operable breast cancer. ISRN Oncol. 2013 Jul 10;2013: 935796. doi: 10.1155/2013/935796. Print 2013.

9. Lee, Kelly D, Gravitt PE, FanslerMatosem JA, Clark DP. Validation of a low-cost, liquid based screening method of cervical intraepithelial neoplasia. Am J Obstet and Gynecol.2006;195(4): 965-70 
10. Kocjan G, Bourgain C, Fassina A, et al. The role of breast FNAC in diagnosis and clinical management: a survey of current practice. Cytopathology. 2008 Oct;19 (5): 271-8. doi: 10.1111/j.1365-2303.2008.00610.x.

11.Simsir A, Rapkiewicz A, Cangiarella J. et al. Current utilization of breast FNA in a cytology practice. Diagn Cytopathol. 2009 Feb;37(2):140-2. doi: 10.1002 /dc. 20987.

12. Rosa M, Mohammadi A, Masood S. The value of fine needle aspiration biopsy in the diagnosis and prognostic assessment of palpable breast lesions. Diagn Cytopathol. 2012 Jan;40(1):26-34. doi: 10.1002 /dc. 21497. Epub 2010 Nov 2.

13. Gerhard R, Schmitt FC. Liquid-based cytology in fine-needle aspiration of breast lesions: a review. Acta Cytol. 2014;58(6):533-42. doi: 10.1159/000362805. Epub 2014 Aug 9.

14. Montes MA, Cibas ES, DiNisco SA, Lee KR. Cytologic characteristics of abnormal cells in prior "normal" cervical/vaginal papanicolaou smears from women with a high grade squamous intraepithelial lesion. Cancer 1999;87:56-59.

15. Ren S, Solomides C, Draganova-Tacheva R, et al. Overview of nongynecological samples prepared with liquid-based cytology medium. Acta Cytol. 2014;58 (6):522-32. doi: 10.1159/000363123. Epub 2014 Aug 9.

16. Arul P. Utility of manual liquid-based cytology and conventional smears in the evaluation of various fineneedle aspiration samples. J Cytol2016;33(4):177-81.

17. Garbar C, Remmelink M, Mascaux C. et al. Fine needle aspiration cytology of lymph node: experience of 2 university hospitals with conventional smears and liquid-based cytology. Acta Cytol. 2008 Jul-Aug;52(4): 418-23. DOI:10.1159/000325546

18. Dey P, Luthra UK, George J, et al. Comparison of ThinPrep and conventional preparations on fine needle aspiration cytology material. Acta Cytol. 2000 JanFeb;44 (1):46-50. DOI:10.1159/000326224

\section{Original Research Article}

19. Perez-Reyes N, Mulford DK, Rutkowski MA, et al. Breast fine-needle aspiration. A comparison of thinlayer and conventional preparation. Am J Clin Pathol. 1994 Sep;102(3):349-53. DOI:10.1093/ajcp/ 102. 3.349

20. Biscotti CV, Hollow JA, Toddy SM, et al. ThinPrep versus conventional smear cytologic preparations in the analysis of thyroid fine-needle aspiration specimens. Am J Clin Pathol. 1995 Aug;104(2):150-3. DOI:10. 1093/ ajcp/104.2.150

21. Lee KR, Foster RS, Papillo JL. Fine needle aspiration of the breast. Importance of the aspirator. Acta Cytol. 1987 May-Jun;31(3):281-4.

22. Mygdakos N, Nikolaidou S, Tzilivaki A, et al. Liquid Based Preparation (LBP) cytology versus Conventional Cytology (CS) in FNA samples from breast, thyroid, salivary glands and soft tissues. Our experience in Crete (Greece).Rom J Morphol Embryol. 2009;50(2):245-50.

23. Koybasioglu F, Onal B, Simsek GG, Yilmazer D, Han $\mathrm{u}$. comparison of thinprep and conventional smears in head and neck fine needle aspiration cytology. Turk Pathology Derg.2008;24(3):159-65

24. Rossi ED, Raffaelli M, Zannoni GF, et al. Diagnostic efficacy of conventional as compared to liquid-based cytology in thyroid lesions: evaluation of 10,360 fine needle aspiration cytology cases. Acta Cytol. 2009 Nov-Dec; 53 (6):659-66. DOI:10.1159/ 000325407

25. Jing X, Wey E, Michael CW: Diagnostic value of fine needle aspirates processed by ThinPrep ${ }^{\circledR}$ for the assessment of axillary lymph node status in patients with invasive carcinoma of the breast. Cytopathology. $2013 ; 24(6): 372-376$

26. Shukla S, Einstein A, Shukla A, Mishra D. Comparison of specimen adequacy and smear quality in oral smears prepared by manual liquid-based cytology and conventional methods. Journal of Oral and Maxillofacial Pathology. 2015;19(3):315-318.

\section{How to cite this article?}

Bindhuja J, Aswathy Jeyachadran. Validity of UPREP liquid based cytology in FNAC examination for palpable lesions type of article- original article. Trop J Path Micro 2019;5(5):300-308.doi:10.17511/jopm.2019.i05.08. 